\title{
Evolution of Safety Management and Systems in a Steel Production Organization
}

\author{
Pekka Tervonen*, Harri Haapasalo and Maarit Niemelä
}

Rautaruukki Plc, P.O. Box 93, FI-92101 Raahe, Finland

\begin{abstract}
The objective of this research was to examine the development of safety management in case company Production division. The emphasis is on the present situation and the purpose was to give a general view of safety management. The idea was also to create practical implications as development focuses for the future. The theoretical background of this research is based on organizations, management and leadership, safety culture, safety management systems and risk management. The safety management systems and methods and the historical background were reviewed. The case description is based on ten interviews made in four production sites of the case organisation. The interviews were used to create a description of the historical development and the applications of different sectors of safety management. The most important strengths, weaknesses, opportunities and threats are summarized by applying SWOT analysis. The present situation of the corporate safety and security was assessed by means of an applied version of Capability Maturity Model Integration. The future development focuses were created on the basis of theory, interviews, SWOT analysis and CMMI model. Personnel safety, crime prevention, security of premises and safety in case of nondomestic activity are on a low level. Occupational and Environmental safety are on a highest level. Safety actions should be more proactive and systematic.
\end{abstract}

Keywords: Safety management, risk management, safety culture, safety development, corporate safety and security.

\section{INTRODUCTION}

The importance of risk management is increasingly emphasised in enterprises, and the importance of overall safety in the company's profitability, business and competitiveness is significant. The world's leading companies have started to increasingly invest in different sectors of safety, and safety is a central precondition of competitiveness, as well as an integral part of high-quality business operations. Companies are expected to have an open policy in terms of safety, and both the media and clients show particular interest in the fields of industry which contain safety risks. Increasing attention is started to be paid to the level of safety, for example, when assessing new possible co-operation partners $[1,2]$.

Safety can be defined as a state or status of a system in which all business-related risks are at an acceptable level [2]. Safety is mainly related to unintentional accidents, incidents and losses, whereas security contains the aspect of intentional damage, crime and terrorism [3]. Safety management refers to the method of leading a company whereas safety leadership is more of a hypernym which contains the principles of the way of thinking studied here. Safety management combines the different fields of safety into one entity and thus functions as the coordinator of different sectors of safety. Safety management means the protection of people, environment and property as well as determined development of safety. Safety management includes all the areas and operations that are necessary to

*Address correspondence to this author at the Rautaruukki Plc, P.O. Box 93, FI-92101 Raahe, Finland; Tel: +358 405578 911; Fax:+358 205924 185; E-mail: pekka.tervonen@ruukki.com ensure the meeting of the organisation's goals and the intactness of the targets to be protected [3,4].

Corporate safety means the holistic management of all safety issues of a company [5]. The objective of corporate safety is to protect against accidents, harm, misuse and crime and ensure the legitimate operational prerequisites of a company, as well as undisturbed production and operations [1]. Corporate safety is managed by means of safety and risk management [6]. The sectors of corporate safety are personnel safety, rescue operations, safety against crime, data security, safety of buildings and premises, safety of production and operations, occupational safety, safety of non-domestic operations, readiness planning and environmental safety [7]. A separate management model for corporate safety does not exist but, until now, each category has been developed in companies as a separate unit.

There has been some research in connecting TQM and quality management systems together. Also the practical utilization of these quality management systems has gone beyond just fulfilling the needs of standards [8]. However, there is very little research on how evolvement of safety management and the utilisation of management systems have progressed in industry. Therefore our aim is to study the development of safety management in research in recent years as well as reflect it on practical development in one case organisation. Our examination is operationalised on research questions as follows:

- RQ1: what kind of development steps can be noted in the development path of safety management and its systems in general level, 
- RQ2: in proportion, what are the development paths and current state in the Ruukki Production division and finally

- RQ3: what kind of operating models for safety management and models for the corporate safety sectors there might be for Ruukki Production?

The study takes the historical framework and current views of safety management as a business management tool into consideration. Answers to the research questions will be sought from the literature (RQ1), Ruukki's documentation, archives and by means of interviews carried out in different units (RQ2). Our approach is qualitative and the study is descriptive in nature. The objective of the study is to find profound knowledge trough single case.

The theoretical section discusses safety management and corporate safety. First, safety management is described on a general level, after which the tools and methods of different sectors of safety management will be discussed. The liabilities and obligations of corporate safety also play an important part. The literature review also describes the development of legislation in corporate safety in the applicable parts (RQ1). The empirical section of this study describes the development and current status of safety management in case organisation. In addition to the interviews, the data included Ruukki's documentation related to safety management from the company files. The different sectors of corporate safety were analysed using the CMMI maturity level, and the maturity levels of each sector were defined (RQ2). Future operating models were created on the basis of the theoretical section, interviews, SWOT analysis and the CMMI maturity model (RQ3). Former is outlined based on qualitative case study approach $[9,10]$.

\section{SAFETY MANAGEMENT}

\subsection{Safety Culture}

Ruuhilehto and Vilppola [11]. present safety culture model, according to which safety culture is comprised of three sub-systems: safety management system, safety atmosphere and safety attitudes, as well as behaviour [11]. Safety atmosphere and attitudes are psychological factors that cannot be perceived as such, whereas behaviour and management system are visible factors. If one wishes to develop safety culture, the measures taken must be directed at all three sub-systems. The change in the safety culture must be commenced by influencing the operating methods of the organisation and the people in it. A good safety culture is the result of good human resources management and efficient safety management [5]. A company's safety culture can be seen in the personnel's attitude towards safety regulations and the consequent practical arrangements, the management's attitude towards the costs related to safety assurance, the model set by the superiors, position of safety in relation to profitability in decision-making, openness of the attitude towards problems and failures, the level of continuous improvement and learning from mistakes, as well as the questioning of risky operating methods and decisions [2, 12]. Within a positive safety culture, the organisation's formal management systems and leader's informal management practices facilitate caring by encouraging, recognizing, and reinforcing safe behaviour [13].

\subsection{Safety Management System}

Safety management combines different sectors of safety as one entity and thus functions as a coordinator between the sectors. Safety management combines the management of methods, practices and human resources; it consists of continuous planning, action and follow-up. Safety management includes both anticipatory and remedial action in order to continuously improve the working environment. Safety work should be a part of everyday functions integrated in the other work of the unit $[12,14,15]$. According to Hale et al. [16], the focus of safety management lies in regulations, responsibilities, hierarchy of an organisation, plans and policies [16]. In addition to these structural parts, internal factors of an organisation, i.e. social factors, must be taken into consideration. Social factors consist of human resources, handling of problems and conflicts of interest, as well as reconciliation of different goals, values and views. The reconciliations, dependence and interaction of technical and social systems should be taken into account when modelling the operations of an organisation [17, 18].

The objective of safety management systems is to manage the planning and implementation of a company's safety policy. Safety management system may include, for example, the setting and prioritising of the company's safety goals as well as the development of safety programmes. Other important sectors are organisation and communication, which focuses on the definition of responsibilities and the creation of communication channels. A safety management system also aims for the management of examination and assessment [12]. The measurement of the level of safety operations is an integral part of a safety management system because only actions, whose impacts can be metered, can be managed [4].

Reason [19] divides safety management into three different categories: the safety management of a people, machine or equipment and organisation [19]. According to the first model, people have two options to choose from: to do the work in a safe manner or not. In this model, failures are attributed to human actions, such as lack of motivation, lapses of memory or carelessness. The safety management level is often metered by means of accident frequency, and the safety organisation plays a key role. According to the second category, failures are attributed to the interaction between humans and machines, not so much to psychological factors. Safety actions are well characterised by risk analyses and the assessment of environmental impacts on human beings. According to the third category, human error is more a result and it reveals the cause in the system. The organisational model has common points with the total quality management model (TQM), and it emphasises anticipation and continuous improvement of the system. The improvement of both quality and safety will result in a higher level of risk prevention, which creates the basis for an integrated management model. Many authors (e.g. Herrero et al. [20]) defend the idea that the concepts of TQM can be applied to the practices of safety [20].

The first safety management system applications were based on the Occupational Health and Safety Management System (BS 8800) and the Dutch Safety Checklist for Contractors (SCC) standard. BS 8800 was replaced with the in- 
ternational OHSAS specifications in 2000. The Occupational Health and Safety Assessment Series specifications OHSAS 18001 supports the assessment and certification of the management systems of organisations. In addition, the International Labour Organisation (ILO) has published instructions on occupational health and safety systems (ILO-OHS 2001). The International Safety Rating System (ISRS 1996) is a method for auditing safety management procedures and the functionality of the systems. The method can also be applied to environmental and quality issues. The safety practices self-assessment model complements the European Quality Award model by taking the occupational health and safety issues into consideration in a more comprehensive manner [18]. Integration of e.g. occupational health and safety matters into environmental management systems can bring many benefits to industrial companies. They can avoid duplicated measures and find optimal solutions, because the principles of prevention are similar in environmental protection and safety management [21].

\subsection{Successful Safety Management}

Safety management of a company is based on safety policy that should be integrated as a part of company's operations in order to make it consistent with all the company's goals [22]. Reason [19] presents a model in which profitability and the protection of people, environment and property are interdependent. According to the model, the more a company faces high hazard ventures the more it needs to invest in protection. Protection, however, uses the resources of production, such as money and labour, which means that extremes should be avoided in order to be able to meet the profitability of production. However, improving production at the cost of safety may lead to a serious incident or catastrophe [19].

Successful safety management requires the commitment of the management and true actions. If the corporate management is not committed to improve the level of safety, noone will take care of the task. Commitment to the goal should be sincere because, if the management does not genuinely believe that improving safety is profitable, they cannot allocate all the resources needed. The principles of safety thinking should be included in the everyday work of every member of the organisation from the highest management to workers. Safety should not be a separate function or system but a natural part of everyday work [23, 24, 25]. Flin and Mearns' [26] study in offshore environments indicated that the management's commitment to safety, job satisfaction, attitudes to safety versus production and job situation had the greatest effect on workers' perception of risk and their satisfaction with safety measures [27].

Successful companies mainly concentrate on surpassing themselves, not their competitors. Deep examination of operations is more important than the examination of visionary statements. Everyone must understand the expectations and the goals must be set in a clear way. The goals must also be updated if need be, in order to create a positive cycle towards the improvement of the safety level. The meeting of the goals is verified in regular measurements. When safety level is incorporated as an important metric, safety management also becomes important. The building and enhancing the process should have priority, not the results. In terms of safety, this means that one should not only focus on incident statistics. It is more important to analyse the anticipatory metrics of the process. This way, it is possible to gain information on the correctness of the measures taken $[2,25,28]$.

DuPont is one of the leading chemical companies in the world and considered a forerunner in safety. The formation of a safety culture in a company usually takes very long time, but DuPont managed to do it in only two years. This was achieved by replacing the key persons in the management and superior level with people who had well internalised DuPont's safety culture [2]. The development of safety culture is one of the most important factors when aiming for successful safety management [13].

Another important starting point for successful safety operations is the motivation, empowerment and participation of employees in safety work. Personnel can be motivated for safety work, for example, by giving positive feedback and emphasising the financial aspects. A number of studies e.g. Flin et al., [26], Gill and Shergill [30] have confirmed the need to consider not only key organisational factors, but also to take account of individual factors, such as personal appreciation of risks and involvement in safety-related decisions $[26,29]$. It is important for a company to understand that if one wants to develop something, it must be made meaningful for the employees, because otherwise it will be an uphill battle. Employees can be made aware of their importance and trustworthiness by making their positions important, giving them responsibilities and authorisation. In order to be able to give responsibility and authorisation, the personnel must be trained and initiated in safety issues. In order to be able to direct the training in a correct way, training needs must be carefully examined in advance $[18,25]$. Successful safety operations significantly affect job satisfaction and wellbeing at work. The satisfaction and happiness of employees should be taken seriously, because it also greatly affects the profitability of work and financial result. In addition, satisfaction has a direct impact on the number of accidents and failures, which more often occur to dissatisfied employees [25].

According to Lanne et al. [30], the assessment of the company's overall safety mainly lies in occupational safety and healthcare. There are only a few sectors of corporate safety with an implemented, systematic monitoring method, which results in a vague conception of safety issues, in addition to which the benefits of resources invested in safety operations cannot be clearly demonstrated. A great deal of information between different safety operators is needed, which sets requirements for the data management system. The amount of communication and co-operation affect the amount of necessary information. Employees must be informed of ongoing projects and their questions must be answered [30].

\subsection{Tools and Procedures of Corporate Safety}

Kerko [5] defines corporate safety as holistic management of all safety issues of a company. Leppänen [4] uses the concept of organisation safety, in addition to corporate safety. The achievement and manage of corporate safety requires risk and safety management from an organisation. Risk management policy directs the company's safety man- 
agement planning and the success of safety management directs the development of risk management. Safety management and risk management form a mutually directing circle [31]. In addition to safety and risk management, organisational culture, learning and interaction affect the level of corporate safety [6].

The objective of corporate safety is to ensure undisturbed business, support the company's financial goals and ensure the quality of products and services. Well-managed corporate safety also gives a company a good public image. The objectives of corporate safety also include protecting against accidents, harm, misuse and crime, and ensure the legitimate operational prerequisites of a company as well as undisturbed production and operations. Protective measures can be directed at a person, property, information, environment and the company's reputation. Corporate safety is an integral part of the company's management and competitiveness based on corporate safety policy, corporate safety action plan, unit and section specific operating instructions, reporting system and metrics describing the operations and results. In practice, safety work is a part of everyday work to prevent accidents, near-miss events, damages and to create readiness to act in case of such an event $[1,32]$.

According to Kerko [5], a safety management system built on the foundation of the concept of corporate safety creates grounds for a harmonised management system and ensures that the different sectors of safety are referred to using the same terms [5]. In Finland, the Board of Corporate Security divides corporate safety into ten categories: personnel safety, rescue operations, safety against crime, data security, safety of buildings and premises, safety of production and operations, occupational safety, safety of non-domestic operations, readiness planning and environmental safety [7]. The categories have been divided in a slightly different manner in different sources, but the Board's classification is usually used as the basis in Finland. The different sectors of corporate safety have developed separately and at different speed e.g. environmental safety and data security issues have been developed as separate management systems $[5,30]$.

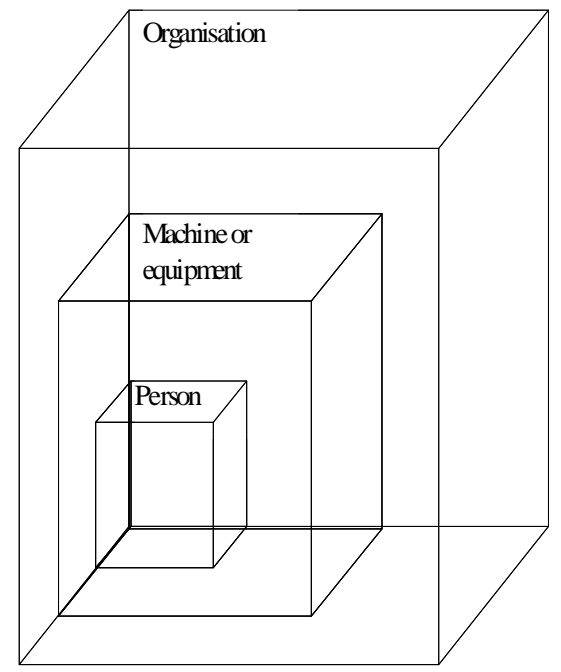

Fig. (1). Classification of the scope and development level of the safety management.

\subsection{Development Steps of Safety Management and Sys- tems}

Reasons [19] classification describes the development in extent of safety management; people, machine or equipment and organisation (Fig. 1). The extent of which safety is dedicated describes also the complexity. First level focuses on people, weather they are working safe on not. Second level includes also machine and equipment to people, then the safety is related on connection between them. On organisational level error or mistake is consequence of fault hiding in the entire system [19].

The operating cultures in different sectors of safety differ considerably, and legislation usually only governs the safety regulations of a single sector. This sets challenges for the successful implementation of the corporate safety of a company. A general overview on the commencement of the development path of legislation-making concerning different fields of safety in Finland (Table 1). This is also the devel-

Table 1. Commencement of the Development Path of Legislation-Making Concerning Different Sectors of Corporate Safety in Finland (Scale: x Poor, xx Fair, xxx Good, xxxx Very Good, xxxxx Excellent)

\begin{tabular}{|c|c|c|c|c|c|c|c|c|}
\hline Sectors & 1930 & 1940 & 1950 & 1960 & 1970 & 1980 & 1990 & 2000 \\
\hline Personnel security* & & & & & & & & $\mathrm{x}$ \\
\hline Rescue operations & $\mathrm{x}$ & & $\mathrm{x}$ & $\mathrm{X}$ & $\mathrm{x}$ & & $\mathrm{xx}$ & $\mathrm{xx}$ \\
\hline Safety against crime ${ }^{* *}$ & & & & & & & & $\mathrm{x}$ \\
\hline Information security & & & & & & & $\mathrm{x}$ & $\mathrm{xxxx}$ \\
\hline Safety of buildings and premises & & & & & & $\mathrm{x}$ & & $\mathrm{xx}$ \\
\hline Safety of production and operations & & & $\mathrm{x}$ & $\mathrm{xx}$ & $\mathrm{xxx}$ & & $\operatorname{xxxxx}$ & $\mathrm{xx}$ \\
\hline Occupational health and safety & $\mathrm{x}$ & $\mathrm{x}$ & $\mathrm{x}$ & & $\operatorname{xxxxx}$ & & & $\mathrm{xx}$ \\
\hline Safety of non-domestic operations $* * *$ & & & & & & & & $\mathrm{x}$ \\
\hline Readiness planning & & & & $\mathrm{x}$ & $\mathrm{x}$ & & $\mathrm{xx}$ & $\mathrm{x}$ \\
\hline Environmental safety & & & & & $\mathrm{x}$ & $\mathrm{x}$ & $\mathrm{xx}$ & $\mathrm{xx}$ \\
\hline
\end{tabular}

$\mathrm{x}=$ commencement and reform level of legislation

$*$ is connected to occupational health and safety and information security

** is connected to general crime legislation

*** is connected to personnel security, safety against crime, rescue operations and safety of production and operations 
opment of the content in safety management in the past. Further conclusion is that the development follows the progression of legislation and regulations. Then the organisational development is passive - defined outside the organisation (regulators and government). Only in recent years development has lead on more active approach inside organisation from its own origins. Individual methods beyond authority regulations can lead on sustainable competitive advantage, which includes multiple approaches on entity of safety and security. These approaches overlap and support each others and strict running after the regulations might result unnecessary double work. One reason might be mixed use of same concepts in different areas of security.

Several different parties participate in safety operations of large companies, and the different sectors of safety, as well as risk assessment, is often treated in a number of places around the organisation. In addition, risk assessment often addresses risks from the viewpoint of only one sector of safety, and the results of a single assessment do not reach the different representatives of the safety organisation. Evaluation of the different sectors of safety may lead to a situation in which improvements are only made in the sector evaluated at a given time. The impacts of the measure on the overall safety of the organisation are not taken into consideration. In terms of overall safety, the best solutions can be found by assessing the impacts of an improvement on all sectors of safety. The goal is to avoid overlapping work in risk assessment in different sectors of safety and waste of resources. More holistic management of safety issues can be achieved by increasing co-operation between people responsible for different sectors of safety [23, 33].

\section{MATERIALS AND METHODOLOGY}

Our study leans on literature review on safety management and systems. In the end of review we synthesise general development as an entity. Based on former we outline content for empirical analysis on our case organisation. First we have analysed documentation and material already existing in case organisation related on safety management and systems (Fig. 2). Already on that phase it was obvious that documentation and practical application are differing. However, the literature review (Especially "Occupational health and safety systems OHSAS 18001 workbook") and company specific material analysis as a baseline an organisation specific questionnaire was created (see Appendix). Questionnaire was also validated by company representatives. In total 12 interviews were performed as personal face to face interviews, which were recorded and also summarised after interviews. Informants were representing different levels in organisation, but all having at least partial responsibility on safety issues. Informants were also representing different sectors of safety in organization. Questionnaire was e-mailed to informants before interviews, in order get profound knowledge from practice. Questionnaire was divided on three parts, where first was aiming on describing the development of sectoral safety issues and safety management in our case. Second part was aiming on describing the current state of different sectors more accurately and last part was aimed to provide practical views on developing safety management in our case.

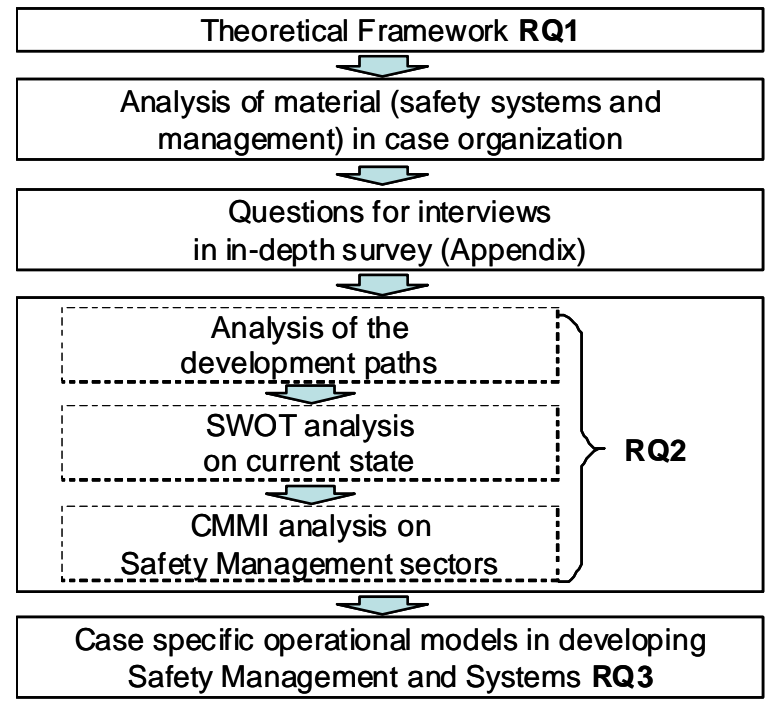

Fig. (2). Progression of the research process.

Our analysis is qualitative and descriptive in nature and we follow what Yin [34] has presented for case study set up. The objective of our analysis is to find profound knowledge trough single case. In practise this study also utilises Cunningham's four intensive methods (narrative, tabling, explanatory and interpretive case) for the making of a case study described in Jarvinen and Jarvinen [10]. First part of our analysis was created based on organisations internal material and our survey, in order to create description of development safety issues and compare it to theoretical findings (see Fig. 2). Mainly second part of our survey provided information to SWOT analysis to outline development challenges and CMMI [5,35] analysis to compile maturity of different sectors of safety. Third part of our questionnaire was searching development potential inside the organisation. Based on these case specific findings, future operational models and issues were outlined comparing findings from literature.

\section{RESULTS - DEVELOPMENT OF SAFETY MAN- AGEMENT IN CASE ORGANISATION}

Rautaruukki specialises in the production of metal-based components, solutions and turn-key deliveries to the engineering workshop and construction industries. The company's turnover in 2006 was approximately 3.7 billion euros, it had operations in 23 countries and it employed about 13,000 people. Ruukki Production manufactures hot and cold rolled surface coated sheet and strip products for divisions, which are responsible for the customers. Production has a steel works in Raahe as well as 10 other production units in Finland, Sweden and Ukraine. In this study, the development of safety management is examined in four Ruukki Production units: Hämeenlinna, Oululainen, Pulkkila and Raahe [36].

The empirical part of the study is twofold including both qualitative and quantitative analysis. The qualitative part is illustrating a common conception of safety management in studied companies, but also analyses the differences between 
companies, and possible root causes of the differences. The quantitative part of study concentrates to recognise the importance and current state of certain function of safety management in studied companies.

\subsection{Development of Safety Management}

At the beginning of Rautaruukki's business in the 1960's and 1970 's, attention was mainly paid to occupational safety, rescue operations and readiness planning. To summarise, attention was mainly drawn to single risk factors and reactions to problems always occurred after the problem. In the 1980's emphasis was still on labour protection, which was targeted at physical protection of employees from dangers. Environmental safety and mental wellbeing of employees were increasingly taken into account at the end of the 1980 's. There were no large-scale changes from the point of view of legislation and Ruukki compared to the previous decades. Reason's [19] safety management model from the human perspective well describes the development of safety management in Rautaruukki until the 1980's, because work was either done in a safe way or not: people had the chance to choose their own behaviour. In addition, a safety organisation played a key role and the level of operations was, to some extent, measured using accident frequency [19].

In the 1990's, quality and environmental issues were independently developed, thanks to the certification of quality and environmental management systems, which also resulted in the increasing awareness of safety issues. The labour protection and environmental policies of the Rautaruukki Group were published in the mid 1990's. Labour safety in particular developed considerably, and operations were characterised by the zero accident -thinking and ability to work actions. In addition to the aforementioned sectors, investments were made in rescue services, data security developed due to the increasing number of computers and more attention was paid to guarding and access control. Legislation in the fields of rescue services, safety of production and operations, occupational safety, readiness planning and environmental safety evolved. The development of access control, guarding and data security was independent from legislation, and labour safety was enhanced more than required by law. Reason's [19] model of the safety management of equipment and machines describes the 1990's well, because risk analyses were started to be made and increasing attention was paid to the impacts of the environment on the employee [19].

Increasing investments in the different sectors of corporate safety were made in the 2000's, the focus still being on labour and environmental safety. The new Occupational Safety and Health Act was made in the 2000's, which means that important investments in the development of the said sectors were made also in terms of legislation. Laws were also made to regulate the other sectors, for example, data security, safety of premises and readiness planning, because of which some attention was paid also to these sectors. There is no actual legislation concerning the safety of human, criminal and non-domestic actions, apart from the common legislation. These sectors were found to be in the weakest position in Ruukki Production. The development of safety has recently been voluntary and people are no longer satisfied with merely meeting the minimum requirements. Laws and regulations have developed more alongside the development of safety procedures than before them. Since safety problems are nowadays more complex, regulations increasingly focus on prevention rather than detailed orders. Reason's [19] model of the organisational perspective of safety management describes safety operations and their goals in the 2000's. The reasons for this are similarities in the development of quality management systems and preventive actions [19]. Development of corporate safety sectors in Ruukki Production are compiled in Table 2.

\subsection{Current State of Safety Management}

Ruukki Production's strengths, weaknesses, external threats and opportunities were mapped using SWOT analysis (Table 3). The strengths should be further strengthened and opportunities exploited in the scope of resources available. When strengths and opportunities combine, the company's relative competitive advantage is created. Weaknesses

Table 2. Development of Corporate Safety Sectors in Ruukki Production

\begin{tabular}{|c|c|c|c|c|}
\hline Sectors & $1960 / 1970$ & 1980 & 1990 & 2000 \\
\hline Personnel security & & & & ++ \\
\hline Rescue operations & + & + & ++ & +++ \\
\hline Safety against crime & & & & ++ \\
\hline Information security & & + & + & ++ \\
\hline Safety of buildings and premises & & & + & + \\
\hline Safety of production and operations & & & & ++ \\
\hline Occupational health and safety & + & ++ & +++ & ++++ \\
\hline Safety of non-domestic operations & & & & + \\
\hline Readiness planning & + & + & + & ++ \\
\hline Environmental safety & & + & +++ & ++++ \\
\hline
\end{tabular}

level $=+$ poor, ++ quite poor, +++ average, ++++ good, +++++ excellent 
Table 3. SWOT Analysis of the Current Status of Safety Management in Ruukki Production

\begin{tabular}{|c|c|}
\hline $\begin{array}{l}\text { Strengths } \\
\text { - Occupational and environmental safety } \\
\text { - Rescue operations and readiness planning } \\
\text { - Audits and follow-up procedures } \\
\text { - Effective communication of information } \\
\text { - Operations of line organisation } \\
\text { - Ability to make decisions }\end{array}$ & $\begin{array}{l}\text { Weaknesses } \\
\text { - Management's commitment to corporate safety } \\
\text { - Organisational culture and attitudes } \\
\text { - Unclear policies, principles and responsibilities } \\
\text { - Personnel safety, crime safety, safety of premises and non-domestic opera- } \\
\text { tions } \\
\text { - Appreciation of efficacy over safety }\end{array}$ \\
\hline $\begin{array}{l}\qquad \text { Opportunities } \\
\text { - Rescue operations, data security, safety of production and operations, } \\
\text { readiness planning } \\
\text { - Clear division of responsibilities } \\
\text { - Safety in everyday actions } \\
\text { - Co-operation between people responsible for different sectors of } \\
\text { - safety } \\
\text { - Benchmarking } \\
\text { - Dotivating, empowering and committing of the personnel }\end{array}$ & $\begin{array}{l}\text { Threats } \\
\text { - An sector of safety with a good current level will be tramped by other sectors } \\
\text { - The importance and development needs are not understood } \\
\text { - Threats created by internationalisation } \\
\text { - No interest in development } \\
\text { - Large retiring age groups } \\
\text { - Many units of different sizes operating in different levels of development and } \\
\text { - } \text { different cultures }\end{array}$ \\
\hline
\end{tabular}

should be identified in order to be able to minimise their impacts and threats should be prepared for in order to be able to avoid them as easily as possible [37].

\subsection{Maturity Levels of Sectors of Corporate Safety}

CMMI is a maturity model developed for the improvement of the operations of organisations. It helps to develop processes from one level to another in a systematic manner [35]. The levels of corporate safety of Ruukki Production evaluated on the basis of the CMMI maturity model are compiled in Table 4. The level values of the matrix do not only describe the maturity value of the sector but also the development stage of safety thinking and safety culture. Good corporate culture is the result of good human resources management and efficient safety management [5]. The strongest sectors of Ruukki Production's corporate safety are occupational safety and environmental safety. Personnel safety, crime safety, safety of premises and non-domestic operations were found to be the weakest sectors of corporate safety.

\subsection{Safety Management Operating Models}

Fig. (3) shows the interdependences between the operating models suggested for safety management as well as the relation between benefits and costs. The most

Table 4. The Levels of Corporate Safety in Ruukki Production

\begin{tabular}{|c|c|c|c|c|c|c|}
\hline Corporate Safety Sector & $\begin{array}{l}\text { Strategies } \\
\text { Policies }\end{array}$ & Processes & $\begin{array}{c}\text { Organisa- } \\
\text { tion People }\end{array}$ & $\begin{array}{l}\text { Management's Decision } \\
\text { Making Information }\end{array}$ & $\begin{array}{l}\text { methodologies } \\
\text { Methods }\end{array}$ & IT Systems Data \\
\hline Personnel & Below level & Below level & Below level & Initial & Below level & Below level \\
\hline Rescue & Defined & Defined & Defined & Defined & Defined & Repeatable \\
\hline Crime & Below level & Below level & Below level & Initial & Below level & Below level \\
\hline Data & Managed & Initial & Below level & Managed & Initial & Repeatable \\
\hline Premises & Below level & Initial & Below level & Initial & Initial & Below level \\
\hline Operations & Defined & Repeatable & Repeatable & Defined & Defined & Repeatable \\
\hline Work & Optimizing & Optimizing & Managed & Optimizing & Optimizing & Managed \\
\hline Non-domestic operations & Below level & Below level & Below level & Initial & Below level & Below level \\
\hline Readiness planning & Defined & Repeatable & Repeatable & Initial & Repeatable & Initial \\
\hline Environ-ment & Optimizing & Optimizing & Managed & Managed & Optimizing & Managed \\
\hline
\end{tabular}

\begin{tabular}{|c|c|c|c|c|c|c|}
\hline Scale: & Optimizing & Managed & Defined & Repeatable & Initial & Below the level \\
\hline
\end{tabular}




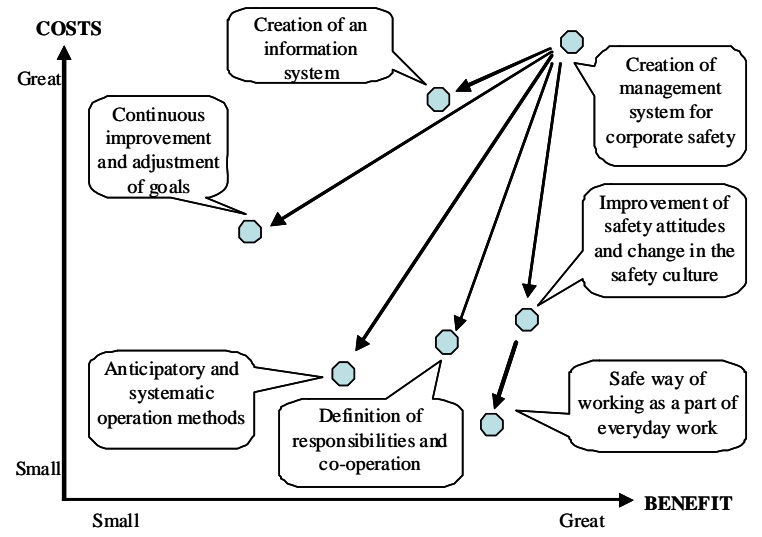

Fig. (3). Costs and benefits of safety management operating models in Ruukki Production.

important dependences between the models are illustrated with arrows. After the development of a corporate safety management system, it is easier to start developing the other sectors of safety management because other operating models presented are, in principle, created along the management system. Modelling of safety management systems is seen as a set of problem solving activities at different levels of abstraction in all phases of the system life cycle. Also, the safety management system shows the inputs, resources and criteria and constraints necessary to produce the required outputs. In addition, risks are modelled as deviations from normal or desired processes [16]. Safety attitudes and culture are the second in terms of benefits, directly after the management system, because they have a great influence on all safety-related actions for which they also create a basis. According to Choudhry et al. [13], research in safety culture is generally considered to influence employees' attitudes and behaviour in relation to an organisation's ongoing health and safety performance. When considering developing operating models, attention should be paid to the relation between risks and benefits in order to be able to define the correct order of priority for development points [13]. According to Reason's model the more a company faces high hazard ventures the more it should invest in protection [19].

\subsection{Operating Models for the Corporate Safety Sectors}

Fig. (4) presents the relation between the benefit gained from the development of the different sectors of corporate safety and the costs generated in the process. Costs are mainly created in the development of such sectors that are the weakest in the current position. On the other hand, in some cases the greatest benefits can also be gained in the development of these areas. Continuous development of sectors that are on a good level and adjustment of goals are essential factors in maintaining the good level achieved. The costs and benefits are smaller that those related to weaker sectors, but if the maintenance, continuous improvement and adjustment of goals are forgotten, it will cause significant harm. The integrated risk management and security analysis package represents an objective and sensible approach to a complicated problem which allows risks to be managed in a logical, cost-effective manner. In order to be effective, the process requires total commitment from the highest levels of the management structure - management must accept the responsibility for the problem as well as participate in the solution [23].

\section{DISCUSSION}

The most important contribution of the work was to compile the development, current status assessment and suggested future operating models concerning Ruukki Production's safety management in one document. The study includes the mapping of the development of safety management in Ruukki which has been compared to the development of legislation in corporate safety. The current status was mapped by means of interviews and suggestions for future operating models were collected by comparing the current status with the literature and good practices. The study contains a considerable amount of new information for almost all people responsible for safety issues in an organisation, mainly because corporate safety is a relatively new subject and different people are responsible for different sectors. Repeating the same mistakes can be avoided by knowing the history.

In terms of safety management, this study discussed the systems and operating methods currently in use, as well as their development. The literature gave a profound answer to questions related to safety management and its development. The objective of this part of the study was to form a background for the management of corporate safety of Ruukki Production and to define the related good practices. Corporate safety was examined from the viewpoint of different sectors and the tools and methods of various sectors of corporate safety were reviewed. The variety of literary references for corporate safety was significantly narrower and the time span shorter. This part of the study can be used in Ruukki Production as an information package for each sector of corporate safety.

A rather extensive answer was received concerning the history and current status of safety management in Ruukki Production. All in all, the development of legislation well describes the development of corporate management in particular in the beginning of operations. Thanks to the mapping of the safety management history, it is possible to better understand the background of different sectors of corporate safety and the factors influencing their development. The

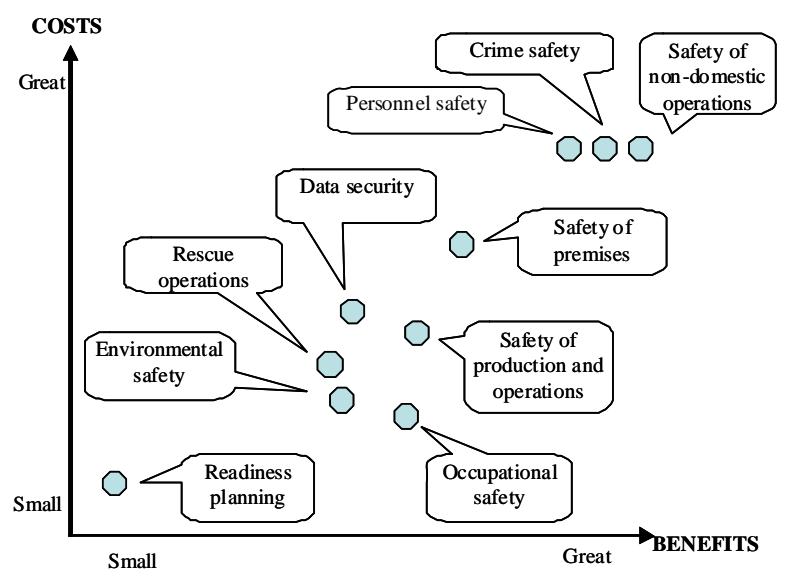

Fig. (4). Costs and benefits of the development of corporate safety operating models in Ruukki Production. 
pros and cons of safety management and corporate safety can be found in the modelling of the current status, and thus target the future measures at the correct places. To put it briefly, safety management in Ruukki should be more proactive and systematic. The measurement of a safety culture is categorized under the proactive approach of safety performance [13]. In terms of corporate safety, Ruukki Production's strongest sectors are occupational and environmental safety. The weakest points were personnel safety, crime safety and safety of premises and non-domestic operations. Management has a key influence on safety culture and management [38, 39]. Efficient and successful safety management depends largely on the attitudes and the commitment to safety that exist in the organisation [40-43].

Future operating models were created on the basis of theory, interviews, SWOT analysis and CMMI maturity model. Thanks to operating models and development alternatives, the level of safety management and corporate safety can be improved, in addition to which Ruukki can use them to map potential targets for development. In terms of safety management, the building of a corporate safety management system and the development of safety culture were raised as the most important future operating model alternatives. Safety management and the building of a management system combine the different sectors of safety into one and thus works as a coordinator between the sectors [12, 14, 15]. The development of a safety culture is one of the most important factors in order to achieve successful safety management. Choudry et al. [13] demonstrate that developing a positive safety culture can be an effective tool for improving safety. Within a positive safety culture, employees not only feel responsible for their own safety, but are responsible for their peers' safety and the organisational culture supports them acting on their responsibility. Within a positive safety culture, the organisation's formal management systems and the leader's informal management practices facilitate caring by encouraging, recognizing and reinforcing safe behaviours [13]. Afrazeh and Bartsch [44] shows in their research that it is necessary provide the required internal and external conditions for the promotion of human reliability and productivity. Internal conditions are individual factors as willingness, motivation, expertise, experience, consciousness, physical and psychological capabilities, workmanship etiquette, readiness for team and individual works. External conditions are related to organization and environment such as technical issues (equipments, devices, work, machine) and organizational issues (policies, structure, trends and educational, evaluation and remuneration system and management and leadership strategy) [44].

When evaluating the structural validity of this study, it can be stated that several sources have been used for the creation of the theoretical framework, as well as for the compilation of empirical data. The accuracy of causal relationships related to the validity of the study has been improved by interviewing several persons and making summaries of their responses. The external validity, i.e. the possibility to implement the results in a wider context, is limited to Ruukki Production. The objective of the study is to present a view of the overall development of the division, which means that discussion on a very general level cannot be avoided. The reliability of the study was aimed to be im- proved by means of anonymity of the subjects interviewed, by sending the questions in advance, recording the interviews and by preparing for the interviews. The objectives were to process the data in as objective a manner as possible and present the most important issues [34].

\section{CONCLUSION}

The overall development of safety management clearly has several levels or extents like Reasons [19] people, machine or equipment and organisation. However, at least in Finland, the development has mainly been striven by the legislation and regulations. This means that the safety management systems have evolved reactive but not proactive utilisation has emerged - not until recent years, where safety management has been integrated to other system level issues like quality and environmental systems. This leads safety management also closer to risk management. In recent years proactive utilisation of safety management issues leads on competitive edge in business level of organisation.

The development of safety management in Ruukki follows the descriptions and mapping found from literature. Partially this is because of compulsory legislative regulations. Yet proactive leaps were not identified in great extent. However currently it seems to move on more proactive and systematic direction, e.g. some measurement activities have taken place. In terms of corporate safety, Ruukki Production's strongest sectors are occupational and environmental safety. The weakest points were personnel safety, crime safety and safety of premises and non-domestic operations.

Future operating models were created on the basis of theory and our study. We can also clearly point out some development activities and also most important areas, which Ruukki can use them to map potential targets for development. Naming for example the building of a corporate safety management system and the development of safety culture were raised as the most important future operating model alternatives. Azadeh [45] for example demonstrate that management is the key to assuring that risk and reliability, quality engineering, human engineering and teamwork program function properly [45]. Safety management and the building of a management system combine the different sectors of safety into one and thus works as a coordinator between the sectors. We have to naturally continue our study to other organisations, but also go deeper on Ruukki's systems. Based on our study, the message for other organisations is that safety management's highest purpose and its real contribution to business is providing a framework that helps the company understand and acquire these safety issues as part of an integrated business management.

\section{APPENDIX}

\section{Development Path and Current State of Safety Systems and Safety Management}

\section{Part A: History and General Methods of Safety and Secu- rity Actions}

1. How has safety actions developed (in this unit/division) during last decades? What principles of safety and security has there been in each period? When actual safety/security policy or -management system was introduced? 
2. What kind of attitude has every organisation level had towards safety and security in each period? Describe each sector of corporate safety and security (personnel safety, rescue operations, safety against crime, data security, safety of buildings and premises, safety of production and operations, occupational safety, safety of nondomestic operations, readiness planning and environmental safety):
a) Management
b) Line organisation
c) Safety organisation
d) Employees.

3. Are the safety/security issues known in every organisation level and are the instructions easily available? How does the communication work in safety/security issues?

4. Does the organisation culture give support to improve safety and security level? Are the safety and security issues natural part of organisation's daily actions?

5. Are the safety and security development focuses and development methods searched actively and professionally? Are the working conditions and -methods observed? Are the deviations reported and cases investigated?

6. Is the level of safety and security integrated in bonus system? Are the improvements in safety/security level recognised in some other way? What sectors of corporate safety and security are defined to include in the bonus system's determination principles? For informant to be evaluated in scale 1 to 5 (scale: $1=$ not valued at all, $5=$ highly valued).

7. Are the management systems (quality, environment and safety) integrated? Are the connections taken into account or are same things done simultaneously in different management systems?

\section{Part B: Safety and Security Sectors}

8. Following questions were presented towards corporate safety and security sectors (personnel safety, rescue operations, safety against crime, data security, safety of buildings and premises, safety of production and operations, occupational safety, safety of non-domestic operations, readiness planning and environmental safety), for informant to be evaluated in scale 1 to 5 .

9. How are the responsibilities determined in each corporate safety and security sector? Are the responsibilities welldefined and is it implemented in practise (scale: $1=$ no clear definition, nor implemented in practise, $5=$ is clear and implemented in practise).

10. What are the minimum requirements in each sector? Do they satisfy on minimum or is there endeavour on better (scale: 1 = satisfied on minimum, 5 = endeavour on better)?

11. Are there enough resources to be used for each sector? Which sectors have far too less resources? Is there well enough resources in some sector (scale: $1=$ far too less, 5 = well enough)?
12. Does the management system include only occupational health and safety issues or does it cover every corporate safety and security sector (scale: $1=$ not note at all, $5=$ enough coverage)?

13. Are there own management systems in use in some sectors? Is the system and information fragmented or is it uniform (scale: 1 = fragmented, 5 = uniform)?

14. What follow-up actions, regarding safety and security, are there in use in each sector (for example meeting practises, audits, management reviews)? How often are those hold and who participates in these functions (scale: $1=$ not sufficient, 5 = enough)?

15. What kind of document systems, reporting practises etc. are there in use (for example TAVA)? Is there enough documentation and is it adequate? Is it easily understandable, in one place and updated (scale: $1=$ too less and not adequate, $5=$ enough and adequate)?

16. Is the risk evaluation systematic and does it cover each sector in safety and security? Are the results utilised in risk management and is the implementation of actions followed (scale: 1 = bad, 5 = excellent)?

\section{Part C: Development Focuses and the Future}

17. Which sectors of corporate safety and security need the most improvements? Which sectors are in very good level? How does the future of safety and security management look like?

\section{REFERENCES}

[1] Laatunen L. Corporate security grounds. [www document]. Available from: <http://www.ek.fi/ ytnk/tiedotteet/ yritysturvallisuuden_perusteet.-php>. [Read On 5.2.2007] 2007.

[2] Simola A. Safety management superior piece of work. Doctoral dissertation. Oulu, Finland: Oulu University Publications 2005.

[3] Naumanen M, Rouhiainen V. Security research roadmap. VTT press releases 2327. Espoo, Finland: Otamedia Publications Ltd 2006.

[4] Leppänen J. Corporate security practice - safety management portfolio. Jyväskylä, Finland: Talentum Media Oy Publications 2006.

[5] Kerko P. Security management. Porvoo, Finland: WAS Bookwell Publications Ltd 2001.

[6] Lanne M. Cooperation in corporate security management Research the need for internal cooperation and the role of large organizations safety in operation. Doctoral dissertation, VTT, Espoo, Finland: Technical Research Center of Finland Publications 2007.

[7] EK YTNK Corporate Security, Business security areas, [www document]. Available from: <http://www.ek.fi/ytnk/yritysturvallisuus/index.php>. [Read on 13.2.2007], 2005.

[8] Tervonen P, Pahkala N, Haapasalo H. Critical incidents in the development of quality management in steel manufacturers' production. Int J Bus Excell 2008; 1(1/2): 106-20.

[9] Olkkonen T. Introduction to the industrial economy, research, 2nd ed. Otaniemi, Helsinki, Finland: University of Technology Publications 1993.

[10] Järvinen P, Järvinen A. Research work on methodological issues Tampere, Finland: I learned workshop book Publications 2000.

[11] Ruuhilehto K, Vilppola K. Safety culture and safety Promotion of the company. Tuk-Publication 1, VTT. Helsinki, Finland: Technical Research Center of Finland Publications 2000.

[12] Oedewald P, Reiman T. Safety critical organizations. The specialfeatures. VTT Publications 593. Espoo, Finland: Otamedia Publications Ltd 2006.

[13] Choudhry RM, Fang D, Mohamed S. The nature of safety culture: a survey of the state-of-the-art. Saf Sci 2007; 45(10): 993-1012. 
[14] Occupational Health. Labor Vocabulary, Otava Printing Works Ltd.: Keuruu 2006.

[15] Security Management, Social Affairs and the Ministry of Health. Labor guides and instructions 35. Tampere, Finland: Small and medium-weight Publications Ltd 2002.

[16] Hale AR, Heming BHJ, Carthey J, Kirwan J. Modelling of safety management systems. Saf Sci 1997; 2(1/2): 121-40.

[17] Gheorghe AV. Integrated regional health and environmental risk assessment and safety management. Int J Environ Pollut 1996; 6: 618-31.

[18] Levä K. The safety management system functioning: strengths and challenges of major developments in hazardous installations. Tuk Publications 1, Helsinki, Finland: Safety Technology Authority Publications 2003; p.163.

[19] Reason J. Managing the risks of organizational accidents, Aldershot, UK: Ashgate Publishing Limited 1997.

[20] Herrero SG, Saldana MAM, Campo M, Ritzel DO. From the traditional concept of safety management to safety integrated with quality. J Saf Res 2002; 33(1): 1-20.

[21] Honkasalo A. Occupational health and safety and environmental management systems. Environ Sci Policy 2000; 3(1): 39-45.

[22] Hämäläinen P, Lanne M. successful safety management; content and practices, The ministry of social affairs and health publications, Tampere University of Technology. Tampere, Finland: Work Publications 2001; 54: p.70.

[23] Hill S, Smith M. Risk management and corporate security: a viable leadership and business solution designed to enhance cororations in the emerging marketplace. Comput Security 1995; 14(3): 199-204.

[24] Mottel J, Long JF, Morrison DE. Industrial safety is good business: the DuPont story. New York: John Wiley \& Sons Inc. 1995.

[25] Hansen L. Rate your "B.O.S.S" - Benchmarking organizational safety strategy. Prof Saf 2006; 51(11): 50-7.

[26] Flin K, Mearns K, Fleming M, Gordon R. Risk perception and safety in the offshore oil and gas industry (Offshore Technology Report OTH 94 454) Sudbury HSE Books: 1996.

[27] Flin H, Mearns KJ. Risk perception and safety in the offshore oil industry. Second international conference on health, safety, and the environment in oil and gas exploration. Jakarta, Indonesia: HSE in Oil and Gas Exploration Conference Publications 1994.
[28] Hurst W, Young S, Donald I, Gibson I, Muyselaar A. Measures of safety management performance and attitudes to safety at major hazard sites. J Loss Prev Process Ind 1996; 9(2): 161-72.

[29] Gill GK, Shergill GS. Perceptions of safety management and safety culture in the aviation industry in New Zealand. J Air Transport Manage 2004; 10(4): 231-7.

[30] Lanne M, Koskela M, Tytykoski KS. Nenonen, promote the overall security of the company, Tampere University of Technology. Department of Safety Technology 2004

[31] Lanne M. Towards a unified enterprise security management. Manage Res 2006, 25: 29-53.

[32] Miettinen J. Corporate Safety Manual Jyväskylä: Gummerus Printing Ltd 2002.

[33] Lanne M, Tytykoski K. Co-operation and the overall approach to security risk assessment. Work Hum 2004, 18: 269-79.

[34] Yin RK. Case Study Research: Design and Methods, Second Edition. Thousand Oaks, CA, USA: Sage Publications 1994.

[35] Lindström H. Laatua, IT-maailma, laatua. Kvalita 1. Helsinki, Finland: SFS-Inspecta Sertifiointi Oy Publications 2005.

[36] Ruukki, Rautaruukki www pages. Available from: www.ruukki.com [Read on 8.2.2007]. Helsinki, Finland: Rautaruukki PLC Publications 2007.

[37] Nurmi R. Management as a competitive advantage Uppsala: Mermerus 1992.

[38] Flin R. Danger-men at work: management influence of safety. Hum Factors Ergonom Manufact 2003; 13 (4): 261-8.

[39] Guldenmund FG. The nature of safety culture: a review of theory and research. Saf Sci 2000; 34(1-3): 215-57.

[40] Bailey C. Managerial factors related to safety program effectiveness: an update on the Minnesota perception survey. Prof Saf 1997; 8: 33-5.

[41] Clarke S. Perception of organizational safety: implications for the development of safety culture. J Organ Behav 1999; 20(2): 185-98.

[42] Kirwan B. Safety management assessment and task analysis missing link? Saf Manage 1998; 67-91.

[43] O'Toole M. The relationship between employees' perceptions of safety and organizational culture. J Saf Res 2002; 33(2): 231-43.

[44] Afrazeh A, Bartsch H. Human reliability and flight safety. Intern J Reliabil Saf Eng 2007; 14(5): 501-16.

[45] Azadeh MA. Creating highly reliable manufacturing systems: an integrated approach. Intern J Reliabil Saf Eng 2000; 7(3): 205-22.

Received: February 13, 2009

(C) Tervonen et al.; Licensee Bentham Open.

This is an open access article licensed under the terms of the Creative Commons Attribution Non-Commercial License (http://creativecommons.org/licenses/by-nc/3.0/) which permits unrestricted, non-commercial use, distribution and reproduction in any medium, provided the work is properly cited. 